\title{
Sarcoidosis with Splenic Involvement Diagnosed with Endoscopic Ultrasound-guided Fine-needle Aspiration
}

\author{
Hisanori Matsuzawa, Takashi Goto, Shigetoshi Ohshima, Tomomi Shibuya, Wataru Sato, \\ Mitsuru Chiba, Kenichi Takahashi, Shinichiro Minami and Katsunori Iijima
}

\begin{abstract}
:
Splenic sarcoidosis is often diagnosed by splenectomy or an ultrasound-guided splenic biopsy. However, splenectomy is invasive and costly, and a percutaneous biopsy is sometimes difficult. We herein report a case of splenic sarcoidosis diagnosed with endoscopic ultrasound-guided fine-needle aspiration (EUS-FNA). A 71year-old man was referred to our hospital for abnormal shadows on a chest roentgenogram. Computed tomography showed multiple lesions in the spleen and pulmonary consolidations. Bronchoscopy revealed no definitive diagnosis. We therefore performed EUS-FNA for a splenic lesion that led to the diagnosis. This case suggests that EUS-FNA is useful in confirming the diagnosis of sarcoidosis with suspected splenic lesions.
\end{abstract}

Key words: sarcoidosis, splenic sarcoidosis, endoscopic ultrasound-guided fine needle aspiration

(Intern Med 59: 2077-2081, 2020)

(DOI: 10.2169/internalmedicine.4512-20)

\section{Introduction}

Sarcoidosis is a systemic granulomatous disease diagnosed according to the histological evidence of noncaseating granulomas or compatible clinical manifestations (1). The lungs and mediastinal lymph nodes are the most commonly involved. Extrapulmonary involvement is reported in approximately $30 \%$ of patients, and the abdomen is the most common extrapulmonary site with a frequency of 50$70 \%$ (2). Splenic sarcoidosis is often asymptomatic and may be diagnosed by splenectomy or an ultrasound-guided splenic biopsy (3-5).

Endoscopic ultrasound-guided fine-needle aspiration (EUS-FNA) enables the reliable pathological diagnoses of extra-luminal diseases from the gastrointestinal tract (6). With the advent of EUS-FNA, we have been able to perform biopsies when other imaging techniques either failed to identify lesions or were unable to access them (7). Thus far, only seven cases wherein splenic sarcoidosis was diagnosed by EUS-FNA have been reported (8-11).

We herein report a case of splenic sarcoidosis diagnosed with EUS-FNA.

\section{Case Report}

A 71-year-old man was referred to our hospital for abnormal shadows detected on a chest roentgenogram at a medical examination. He had no symptoms and no specific medical history. His vital signs and physical examination results were unremarkable. Laboratory tests showed that angiotensin-converting enzyme (ACE), human sialylated carbohydrate antigen KL-6 (KL-6) and soluble interleukin 2 receptor (sIL-2R) levels were slightly elevated (Table). The lysozyme value was normal. A urinalysis showed a slight increase in N-acetyl-beta-glucosaminidase and $\beta 2$ microglobulin levels, but no hypercalcemia or pyuria suggestive of renal sarcoidosis. Abdominal computed tomography (CT) showed multiple low-density lesions of variable sizes in the spleen (Fig. 1a). Chest CT revealed patchy consolidations scattered in the right upper lobe (Fig. 1b). He also had mediastinal lymphoadenopathy (Fig. 1c).

We first performed diagnostic bronchoscopy. However, bronchoalveolar lavage fluid and a transbronchial lung biopsy revealed no specific findings suggestive of a definite diagnosis. Therefore, to obtain a pathological diagnosis, we

Department of Gastroenterology, Graduate School of Medicine, Akita University, Japan

Received: January 20, 2020; Accepted: March 23, 2020; Advance Publication by J-STAGE: May 8, 2020

Correspondence to Dr. Hisanori Matsuzawa, h.matsuzawa@med.akita-u.ac.jp 
Table. Patient Laboratory Data on Admission to Our Hospital.

\begin{tabular}{|c|c|c|c|c|c|c|c|}
\hline \multicolumn{2}{|l|}{ Hematology } & \multicolumn{2}{|l|}{ Biochemistry } & \multicolumn{2}{|c|}{ Tumor marker } & \multicolumn{2}{|l|}{ Urinalysis } \\
\hline WBC & $5,200 / \mu \mathrm{L}$ & AST & $37 \mathrm{U} / \mathrm{L}$ & CEA & $3.9 \mathrm{ng} / \mathrm{mL}$ & Specific gravity & 1.02 \\
\hline Neutrophils & $74.5 \%$ & ALT & $34 \mathrm{U} / \mathrm{L}$ & CA19-9 & $224.6 \mathrm{U} / \mathrm{mL}$ & $\mathrm{pH}$ & 6.5 \\
\hline Lymphocytes & $17.7 \%$ & ALP & $261 \mathrm{U} / \mathrm{L}$ & SCC & $0.8 \mathrm{ng} / \mathrm{mL}$ & Protein & $( \pm)$ \\
\hline Monocytes & $4.5 \%$ & $\gamma$-GTP & $45 \mathrm{U} / \mathrm{L}$ & & & Occult blood & $(-)$ \\
\hline Eosinophils & $3.1 \%$ & LDH & $164 \mathrm{U} / \mathrm{L}$ & Serology & & Glucose & $(-)$ \\
\hline $\mathrm{RBC}$ & $4.51 \times 106 / \mu \mathrm{L}$ & Total protein & $7.2 \mathrm{~g} / \mathrm{dL}$ & ACE & $21.7 \mathrm{U} / \mathrm{L}$ & & \\
\hline $\mathrm{Hb}$ & $13.5 \mathrm{~g} / \mathrm{dL}$ & Albumin & $3.6 \mathrm{~g} / \mathrm{dL}$ & s-IL2R & $743 \mathrm{U} / \mathrm{mL}$ & Red blood cell & $<1 / \mathrm{HPF}$ \\
\hline $\mathrm{Ht}$ & $40.6 \%$ & Total bilirubin & $0.8 \mathrm{mg} / \mathrm{dL}$ & KL-6 & $778 \mathrm{U} / \mathrm{mL}$ & White blood cell & 1-4/HPF \\
\hline \multirow[t]{2}{*}{ Plt } & $24.7 \times 104 / \mu \mathrm{L}$ & BUN & $20.8 \mathrm{mg} / \mathrm{dL}$ & Lysozyme & $8.8 \mu \mathrm{g} / \mathrm{mL}$ & Protein / Cr ratio & $0.242 \mathrm{~g} / \mathrm{gCr}$ \\
\hline & & $\mathrm{Cr}$ & $0.73 \mathrm{mg} / \mathrm{dL}$ & & & NAG & $9.5 \mathrm{IU} / \mathrm{L}$ \\
\hline Coagulation & & eGFR & $80.5 \mathrm{~mL} / \mathrm{min} /$ & $.73 \mathrm{~m} 2$ & & $\beta 2$-microglobulin & $401.0 \mu \mathrm{g} / \mathrm{L}$ \\
\hline PT-INR & 0.99 & Sodium & $140 \mathrm{mEq} / \mathrm{L}$ & & & & \\
\hline PT\% & $101.2 \%$ & Potassium & $4.1 \mathrm{mEq} / \mathrm{L}$ & & & & \\
\hline APTT & $30.5 \mathrm{~s}$ & Chloride & $104 \mathrm{mEq} / \mathrm{L}$ & & & & \\
\hline APTT control & $39.0 \mathrm{~s}$ & Corrected calcium & $9.9 \mathrm{mg} / \mathrm{dL}$ & & & & \\
\hline FDP & $2.7 \mu \mathrm{g} / \mathrm{mL}$ & CRP & $0.57 \mathrm{mg} / \mathrm{dL}$ & & & & \\
\hline D-dimer & $0.75 \mu \mathrm{g} / \mathrm{mL}$ & & & & & & \\
\hline Fibrinogen & $409 \mathrm{mg} / \mathrm{dL}$ & & & & & & \\
\hline
\end{tabular}

WBC: white blood cell, RBC: red blood cell, Hb: hemoglobin, Ht: hematocrit, Plt: platelet, , PT-INR: international normalized ratio of prothrombin time, PT: prothrombin time, APTT: activated partial thromboplastin time, FDP: fibrin degradation product, AST: aspartate aminotransferase, ALT: alanine aminotransferase, ALP: alkaline phosphatase, $\gamma$-GTP: gamma-glutamyltransferase, LDH: lactate dehydrogenase, BUN: blood urea nitrogen, Cr: creatinine, CRP: C-reactive protein, AFP: $\alpha$-fetoprotein, CEA: carcinoembryonic antigen, CA 19-9: carbohydrate antigen 19-9, SCC: squamous cell carcinoma, ACE: angiotensin converting enzyme, s-IL2R: soluble interleukin 2 receptor, KL-6: human sialylated carbohydrate antigen, NAG: N-acetyl-beta-glucosaminidase
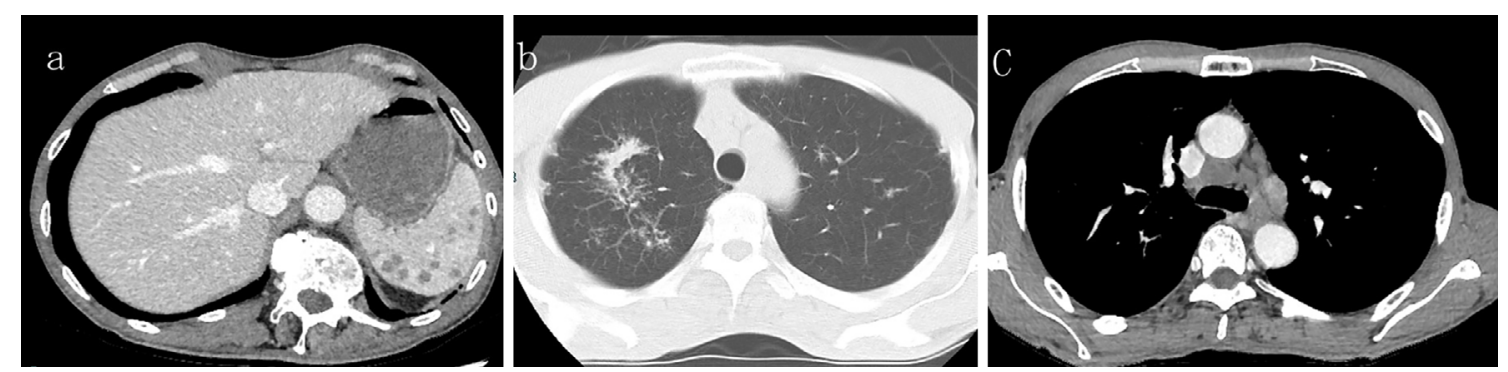

Figure 1. (a) Abdominal computed tomography (CT) showed multiple low-density lesions of variable sizes in the spleen. Chest CT revealed patchy consolidations scattered in the right upper lobe (b) and mediastinal lymphoadenopathy (c).

performed EUS-FNA. On EUS, multiple hypoechoic splenic lesions were seen (Fig. 2a). One pass of EUS-FNA of the spleen lesion was performed with a curvilinear echoendoscope (GF -UCT260 ${ }^{\circledR}$; Olympus Medical Systems, Tokyo, Japan) under conscious sedation through the gastric wall using a 25-gauge Aquire ${ }^{\circledR}$ (Boston Scientific Japan, Tokyo, Japan) (Fig. 2b). There were no complications related to the EUS-FNA procedure. The pathological findings on Hematoxylin and Eosin staining showed non-caseating epithelioid cell granulomas (Fig. 2c). We diagnosed the patient with splenic sarcoidosis based on the EUS-FNA findings.

This case was followed up because there were no symptoms or organ damage. Four months have passed since the diagnosis, and the ACE, KL-6, and sIL2-R levels are largely unchanged (ACE 19.2 U/L, KL-6 652 U/mL, sIL2R 509 U/ $\mathrm{mL}$ ), with CT showing no marked changes in the patchy consolidation scattered in the right upper lung lobe or the low-density lesions in the spleen.

\section{Discussion}

A spleen biopsy is helpful for diagnosing sarcoidosis with suspected splenic involvement. It is especially useful when a diagnosis cannot be determined with basic diagnostic tests, as in this case. The definitive diagnosis of sarcoidosis is based on clinical and radiological imaging findings associated with the histological evidence of noncaseating granulomas (1). Basic diagnostic tests include laboratory tests (ACE, sIL-2R and lysozyme), a transbronchial lung biopsy, bronchoalveolar lavage, and gallium scans (12). In most cases, these tests lead to a definitive diagnosis because the sensitivity of an increased cluster of differentiation (CD)4/ CD8 ratio in bronchoalveolar lavage fluid test is $48-59 \%$, and the specificity is $93-96 \%$ (13), while the diagnostic 


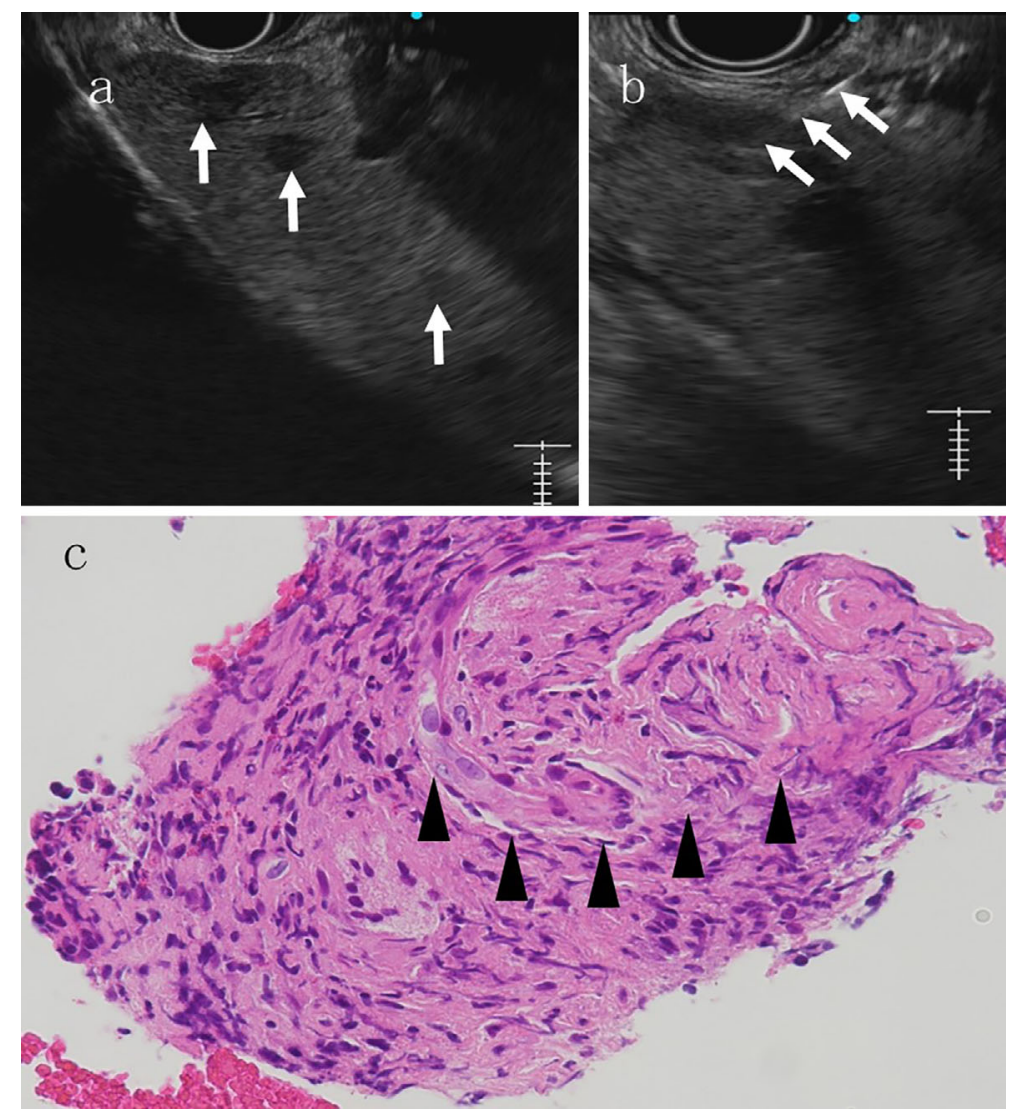

Figure 2. (a) Endoscopic ultrasound (EUS) image showing multiple hypoechoic splenic lesions (white arrow). (b) EUS-fine needle aspiration with a 25-gauge needle (white arrow) was performed. (c) High-power view showing a noncaseating granuloma (arrowheads) (Hematoxylin and Eosin staining, $\times$ 400).

yield of a transbronchial lung biopsy is $78 \%$ (14). However, there are also cases in which a definitive diagnosis cannot be obtained, such as in this case. Heart and nerve biopsies are invasive and carry an increased risk of complications; in contrast, a spleen biopsy has relatively few complications. In such cases, a spleen biopsy is therefore helpful in the diagnosis of sarcoidosis.

EUS-FNA is expected to be useful in the diagnosis of splenic sarcoidosis. Radiological imaging findings of splenic involvement are not specific, and their differentiated diagnosis includes malignant lymphoma, splenic infarction, metastatic tumor, and hemangiomatosis (15). Malignant lymphoma is a major differential diagnosis of splenic lesions. A histopathological diagnosis is important for the diagnosis of malignant lymphoma. The advantage of EUS-FNA is that both cytology and histology can be performed. Three studies have reported the histopathological diagnosis of splenic malignant lymphoma $(9,16,17)$. Seven patients with splenic malignant lymphoma underwent EUS-FNA and were evaluated by cytology, histology and flow cytometry. The needle size differed among the cases (19-gauge or 22-gauge). A diagnosis of lymphoma was achieved in six patients, and subclassification according to the World Health Organization criteria was possible in four patients. Although the number of cases is small due to the rarity of the disease, these find- ings suggest that EUS-FNA is useful for the histopathological diagnosis of splenic malignant lymphoma.

Splenectomy and an ultrasound-guided percutaneous splenic biopsy have been performed to achieve a definitive diagnosis. However, splenectomy is invasive and costly. A percutaneous approach is sometimes difficult because the spleen is not always visible via external ultrasonography and is surrounded by structures such as the lung and colon. For these reasons, EUS-FNA has recently been performed on the spleen, and there have so far been few reports on splenic sarcoidosis diagnosed with EUS-FNA (8-11). These previous reports used either a 19- or 22-gauge needle to diagnose splenic sarcoidosis, and there have been no case reports using a 25-gauge needle. A thicker needle may have been used in the past, since the diagnosis requires histological evidence of epithelioid cell granuloma in splenic sarcoidosis. Theoretically, a small needle would suffer the drawback of a low tissue sampling volume but have advantages of less bleeding and greater flexibility. However, the diagnostic ability and safety of a 25-gauge needle have been reported to show no marked differences from those of 19- and 22-gauge needles $(18,19)$. In the present case, EUS-FNA was performed with a 25-gauge needle to obtain histopathologic materials, and a histological diagnosis of epithelioid cell granuloma was confirmed, leading to a definitive diagnosis. 
Regarding the safety of a percutaneous spleen biopsy and EUS-FNA in cases involving splenic lesions, in a previous multicenter study, ultrasound-guided percutaneous splenic aspiration biopsies were performed in 398 patients (20). For cytological sampling, 22-gauge needles were employed, and 20- and 21-gauge needles were used for histological biopsies. Complications occurred in 21 patients and included hemoperitoneum $(n=3)$, hematoma $(n=2)$, bleeding $(n=1)$, pneumothorax $(n=1)$, vagal crisis $(n=1)$, and mild abdominal pain $(n=13)$. The complication rate was $5.0 \%$ for cytological sampling and $3.9 \%$ for histological biopsies. In another study, a total of 35 percutaneous ultrasound-guided fineneedle aspiration biopsies of splenic lesions were performed (21). All punctures were performed with 22-gauge needles. The complication rate was $2.9 \%$. One patient had significant intra-abdominal bleeding requiring transfusion.

Few reports of splenic biopsy using EUS-FNA have been reported thus far. Fritscher-Ravens et al. (8) performed EUSFNA in 12 patients with splenic lesions. Their study excluded cystic lesions. Using 22-gauge needles, a positive diagnosis was made in 10 of 12 patients (83\%), including 2 cases diagnosed with splenic sarcoidosis. The only adverse effect reported was transient abdominal pain in one patient. Iwashita et al. (9) evaluating EUS-FNA using a 19-gauge needle in 5 patients suspected of having a splenic tumor. The final diagnoses were determined based on the EUS biopsy results in all five cases and included two cases of splenic sarcoidosis. There were no serious complications related to the procedure. Only one patient had mild transient abdominal pain the day after the procedure. Rana et al. (10) reported the results of EUS-FNA for splenic hypoechoic lesion in eight patients. A 22-gauge needle was used in 6 patients, while a 25-gauge needle was used in 2. All patients had their diagnosis determined based on the EUS-FNA findings. Two patients were diagnosed with splenic sarcoidosis using a 22-gauge needle. After the procedure, two patients complained of mild transient pain in the left upper abdomen. However, no adverse events occurred. A Korean report of splenic sarcoidosis diagnosed by EUS-FNA using a 22gauge needle did not mention any complications (11). In these previous reports, the diagnostic ability of EUS-FNA for splenic lesion was high and serious complications were not encountered. Therefore, EUS-FNA for splenic lesions is considered useful and safe.

Sarcoidosis is a systemic disease, often involving multiple organs. In this case, it occurred in the lungs and spleen. However, in some cases, lesions are found only in a single organ, in which case it is called isolated sarcoidosis. Isolated splenic sarcoidosis has been reported (22). In these reports, splenectomy and a percutaneous splenic biopsy were performed. EUS-FNA may be also useful in such cases.

In conclusion, we reported a case of splenic sarcoidosis diagnosed with EUS-FNA. A spleen biopsy can help diagnose sarcoidosis with suspected splenic involvement. EUSFNA is useful for confirming the diagnosis of sarcoidosis with suspected splenic lesions.
The authors state that they have no Conflict of Interest (COI).

\section{References}

1. Iannuzzi MC, Rybicki BA, Teirstein AS. Sarcoidosis. N Engl J Med 357: 2153-2165, 2007.

2. Gezer NS, Başara I, Altay C, et al. Abdominal sarcoidosis: crosssectional imaging findings. Diagn Interv Radiol 21: 111-117, 2015.

3. Mikamori M, Tanemura M, Furukawa K, et al. Laparoscopic splenectomy for isolated splenic sarcoidosis: a case report. Int J Surg Case Rep 69: 79-81, 2019.

4. Taavitsainen M, Koivuniemi A, Helminen J, et al. Aspiration biopsy of the spleen in patients with sarcoidosis. Acta Radiologica 28: 723-725, 1987.

5. Jennifer S, Maria $\mathrm{T}$, Lee $\mathrm{C}$, et al. Image-guided percutaneous splenic biopsy and drainage. Semin Intervent Radiol 69: 301-310, 2012.

6. ASGE Technology Assessment Status Evaluation. Tissue sampling during endosonography. February 1997. ASGE. American Society for Gastrointestinal Endoscopy. Gastrointest Endosc 47: 576-578, 1998.

7. Richard AE. EUS-guided FNA. Gastrointest Endosc 60: 267-279, 2004.

8. Fritscher-Ravens A, Mylonaki M, Pantes A, Topalidis T, Thonke F, Swain P. Endoscopic ultrasound-guided biopsy for the diagnosis of focal lesions of the spleen. Am J Gastroenterol 98: 1022-1027, 2003.

9. Iwashita T, Yasuda I, Tsurumi H, et al. Endoscopic ultrasoundguided fine needle aspiration biopsy for splenic tumor: a case series. Endoscopy 41: 179-182, 2009.

10. Rana SS, Sharma V, Sharma R, Srinivasan R, Gupta R. Safety and utility of endoscopic ultrasound-guided fine-needle aspiration of focal splenic lesions: a retrospective analysis. Ann of Gastroenterol 30: 559-563, 2017.

11. Chon HK, Choi KH, Kim TH. Sarcoidosis with splenic involvement diagnosed via endoscopic ultrasound-guided fine-needle biopsy. Korean J Intern Med 33: 449-450, 2018.

12. Wessendorf TE, Bonella F, Costabel U. Diagnosis of sarcoidosis. Clin Rev Allergy Immunol 49: 54-62, 2015.

13. Winterbauer RH, Lammert J, Selland M, Wu R, Corley D, Springmeyer SC. Bronchoalveolar lavage cell populations in the diagnosis of sarcoidosis. Chest 104: 352-361, 1993.

14. Plit M, Pearson R, Havryk A, Da Costa J, Chang C, Glanville AR. Diagnostic utility of endobronchial ultrasound-guided transbronchial needle aspiration compared with transbronchial and endobronchial biopsy for suspected sarcoidosis. Intern Med J 42: 434-438, 2012.

15. Kamaya A, Weinstein S, Desser TS. Multiple lesions of the spleen: differential diagnosis of cystic and solid lesions. Semin U1trasound CT MR 27: 389-403, 2006.

16. Eloubeidi MA, Varadarajulu S, Eltoum I, Jhala D, Chhieng DC, Jhala NC. Transgastic endoscopic ultrasoundguided fine-needle aspiration biopsy and flow cytometry of suspected lymphoma of the spleen. Endoscopy 38: 617-620, 2006.

17. Ban T, Kawakami H, Kubota Y, Sato Y. Impact of Franseen needle on rapid onsite evaluation and histological examination following endoscopic ultrasonography-guided tissue acquisition in patients with splenic malignant lymphoma. Arab J Gastroenterol 19: 91-95, 2018.

18. Ramesh J, Bang JY, Hebert-Magee S, et al. Randomized trial comparing the flexible $19 \mathrm{G}$ and $25 \mathrm{G}$ needles for endoscopic ultrasound-guided fine needle aspiration of solid pancreatic mass lesions. Pancreas 44: 128-133, 2015.

19. Madhoun MF, Wani SB, Rastogi A, et al. The diagnostic accuracy of 22-gauge and 25-gauge needles in endoscopic ultrasound- 
guided fine needle aspiration of solid pancreatic lesions: a metaanalysis. Endoscopy 45: 86-92, 2013.

20. Civardi G, Vallisa D, Bertè R, et al. Ultrasound-guided fine needle biopsy of the spleen: high clinical efficacy and low risk in a multicenter Italian study. Am J Hematol 67: 93-99, 2001.

21. Venkataramu NK, Gupta S, Sood BP, et al. Ultrasound guided fine needle aspiration biopsy of splenic lesions. Br J Radiol 72: 953956, 1999.
22. Jhaveri K, Vakil A, Surani SR. Sarcoidosis and its splenic wonder: a rare case of isolated splenic sarcoidosis. Case Rep Med. Forthcoming.

The Internal Medicine is an Open Access journal distributed under the Creative Commons Attribution-NonCommercial-NoDerivatives 4.0 International License. To view the details of this license, please visit (https://creativecommons.org/licenses/ by-nc-nd/4.0/).

(C) 2020 The Japanese Society of Internal Medicine Intern Med 59: 2077-2081, 2020 